Staying or Leaving: Contributing Factors for U.K. Engineering Students' Decisions to Pursue Careers in Engineering Industry

Cicely Striolo ${ }^{\mathrm{a} *}$, Michaela Pollock ${ }^{\mathrm{a}}$, and Allison Godwin ${ }^{\mathrm{b}}$

${ }^{a}$ Department of Chemical Engineering, University College London, London, UK;

${ }^{b}$ School of Engineering Education, Purdue University, West Lafayette, IN, USA

*corresponding author

Word Count: 11,314 


\section{Staying or Leaving: Contributing Factors for U.K. Engineering Students' Decisions to Pursue Careers in Engineering Industry}

This sequential, explanatory mixed methods study examined students' intentions to stay in or leave engineering industry careers upon graduation. We gathered survey data from 128 second-year engineering students about their intentions and attitudes. The participants were enrolled in a two-week interdisciplinary engineering summer course at University College London called How to Change the World. From this survey, we also interviewed 15 students, eight intending to stay and seven intending to leave, about their intentions and experiences that informed those decisions. We found that students' perceptions of future (motivation), expectations, experiences at university, confidence in their ability to succeed in engineering courses, and sense of belonging in engineering industry were the main contributors to their decisions to stay or leave. The two data streams combined provide a richer picture of how students may be better supported during and through their engineering degree programmes.

Keywords: retention; motivation; belonging; engineering pathways; mixed methods

\section{Introduction}

Students who enter engineering degree programmes often have high motivation for engineering study yet, many do not pursue engineering jobs upon graduation. Numerous studies have investigated reasons students may persist or leave engineering programmes during undergraduate education (Geisinger and Raman 2013; Ohland et al. 2008; Seymour and Hewitt 1997). These studies highlight consistent trends for why students may persist or leave the discipline including an unwelcoming environment, low academic performance, lack of self-confidence in developing skills or preparation, particular interests and career goals, and demographic factors, namely gender and ethnicity. Additional studies explored students' pathways post-graduation, particularly Smith and Gayles (2017) noted that 'one-third of STEM students choose non-STEM paths after graduation' (p. 1201, citing Garibay et al. 2013; Lichtenstein et al. 2009; 
Rayman and Brett 1995). Often students make decisions about their careers for two general reasons: (1) pragmatic, financial decisions and (2) self-expression, matching occupational and personal attributes. In this study, we focus on the second reason that students often choose to stay or depart from their engineering career pathways.

We note that most of the studies that have examined students' decisions to stay in engineering degree programmes or career decisions post-graduation come from a U.S. context. These studies provide a starting point to better understand students' decision making in a United Kingdom context; however, engineering programmes and the considerations that students use to make career decisions may be different based on their national (Downey and Lucena 2005) and institutional climates (Neumann 2001). While the U.S. and U.K. contexts do share similarities in the history and development of engineering, there are differences that may affect how students make career decisions.

Downey and Lucena (2005) highlighted fundamental cultural differences and histories of engineering in France, Germany, England, and the United States that have led to varying national epistemologies in engineering education, and how those differences manifest in the engineer's value in their respective societies. The work highlights that these differences affect and influence engineering students' motivation to choose engineering as a viable degree and future career option. Therefore, we do not assume commonality across countries for engineering students' motivations, expectations of an engineering degree, or engineering identity. We posit that these areas should be challenged and explored in different national contexts.

\section{The United Kingdom Context}

The United Kingdom is facing a shortage of individuals (especially from diverse backgrounds) with engineering skills entering the workforce (EngineeringUK 2018). In 
the EngineeringUK 2018 report, this shortage was especially true in the industrial workforce rather than other possible engineering careers like health/medicine. There is an estimated 36 percent shortfall in the number of engineering graduates versus open positions in the industrial workforce, and this estimate does not include attrition in the transition between higher education and those positions (EngineeringUK 2018).

In January 2018, the U.K. government launched a campaign called the 'Year of Engineering' (U.K. Space Agency 2017). The goal of this campaign was to reshape the public perception of engineering, inspire the next generation of engineers, and present realistic descriptions of engineering careers. The public perception of an engineer is often linked to a narrowly defined set of careers in construction and manual labour sectors (Marshall, McClymont, and Joyce 2007). The term, 'engineer', can both be used to describe someone with a bachelor's degree in engineering that uses scientific and technical concepts to solve complex problems and anyone who builds or fixes things. This linguistic issue has created a context in the United Kingdom that makes defining engineering careers and fostering awareness of and interest in the discipline difficult.

The United Kingdom has struggled not only with graduates entering engineering industry but also participation from women, black and minority ethnic students, and students originally born in the United Kingdom (Osborne and Javid 2015; Royal Academy of Engineering 2016; Humphries-Smith and Hunt 2017). A longitudinal study of U.K. youth found that engineering was seen as a masculine pursuit indicating particular barriers for the participation of women (Francis et al. 2017). A study commissioned by the Royal Academy of Engineering also found that women and students from lower social classes often were less informed about what an engineering career involved and had less well-developed ideas of engineering as a field (Marshall, McClymont, and Joyce 2007). The lack of awareness of engineering career pathways, 
especially for underrepresented groups, highlights a challenge faced by individuals in forming engineering identities and being motivated to choose engineering career pathways.

The difficulty of recruiting UK-born graduates into engineering careers, is particularly striking because $71 \%$ of those entering a first degree in engineering and technology in 2014/15 were of U.K. origin, $6 \%$ from other EU countries and 23\% from other nations (EngineeringUK 2017). Understanding the motivations of students who are from the United Kingdom or European Union (EU) who choose engineering versus students who choose engineering degree programmes from overseas are of particular interest. While many U.K. educational institutions have successful engineering degree programmes, the proportion of students from overseas (non-EU) nations is higher than other STEM areas. Therefore the significant representation of international students in the United Kingdom poses some concerns about the potential impact of changes in future immigration policy and employment within the country to meet industrial needs, especially with the shortfalls in engineering industry professionals outlined above. This trend highlights a particular area for further investigation in this study.

\section{The University College London Context}

The national context is one component for studying students' intentions to stay in or leave engineering career pathways. The institutional context of this study also informs students' intentions. University College London (UCL) overall has high student enrolment numbers (41,539, Full-time 83\%, and Part-time 17\% students), but its faculty of engineering has the highest number of undergraduate students of all $(3,345)$. UCL is located in central London, and markets itself as 'London's Global University', in fact, $32 \%$ of the entire student population is from outside the United Kingdom or EU, and $58 \%$ of the student population identifies as female. However, $69 \%$ of the faculty of 
engineering undergraduates are male, and $48 \%$ of students are from outside the United Kingdom and EU. All statistics reported are from the 2017-18 academic year (G. Smith and Walsh 2018).

\section{Purpose of Study}

The specific contexts of the United Kingdom and UCL have sparked an interest in studying students' intentions to enter into the industrial workforce upon graduation and to understand more deeply the factors that may contribute to staying or leaving that pathway. In this sequential explanatory mixed methods study, we examine how students' engineering identities, future time perspective (motivation), personality, beliefs about their ability to succeed in engineering degrees, and future goals may influence intentions to stay in or leave engineering careers after graduation. We also controlled for common demographic differences among students including gender and ethnicity. We specifically focused on understanding if there are any differences between students' who were from U.K./EU countries and from overseas. We answer the following research questions:

RQ1: What factors predict students' intentions to stay in or leave engineering industrial workforce positions upon graduation?

RQ2: Are these factors different for U.K./EU students and overseas students?

RQ3: How do U.K./EU students and overseas students describe their engineering experiences and reasons for their intentions to stay in or leave the engineering industrial workforce upon graduation?

\section{Conceptual Framework}

In our study, we draw on multiple theoretical frameworks that have been used to either understand students' persistence in engineering or align with understanding how students' self-expression and personal attributes may influence career pathways. We examined students' motivation, personality, identity, outcome expectations and career 
goals. We describe each of the frameworks and how they have been used in prior studies of engineering career interest and persistence below. We used these different theoretical frameworks, which are based on existing theories, to inform our overarching conceptual framework of student decision making and pathways as well as the analysis of the data in this study. We distinguish between these existing theories as 'theoretical frameworks', which have rich histories, traditions, and use in engineering education literature, and our combination of these frameworks in a 'conceptual framework'. This conceptual framework links together these different theoretical perspectives to understand the core questions of this study: students' intentions and pathways upon graduation (Imenda 2014).

\section{Motivation: Future Time Perspective}

We utilised Future Time Perspective theory in measuring students' motivation. This theory examines motivation based on how students formulate distant motivational goals and develop long-range behaviours to achieve those goals (Shell and Husman 2001). This measure is particularly appropriate for understanding how students' current perceptions of engineering align with and dictate their future career pathways.

These motivational profiles are called future time perspectives (FTPs) and are defined by a set of psychological factors: expectancy (belief one will do well in their courses); connectedness (tying current tasks to future goals); instrumentality (current tasks are useful for my emerging identity as an engineer); value (value of future goals over present goals); and perceptions of future (domain-specific valuing of the future). The development of these factors specifically for engineering students are described in more detail in other studies (Benson, Kirn, \& Faber, 2014; Hilpert et al. 2012; Husman \& Shell 2008; Shell \& Husman 2008). It is important to emphasise that motivation is contextually dependent, so using motivation theories and measures developed for 
engineering students provides a better understanding of how current attitudes and beliefs affect goals and actions.

This framework incorporates two of the commonly used measures to frame motivation, expectancy and value (Brown, McCord, Matusovich, \& Kajfez 2015), while also including other, more engineering-specific factors (i.e., instrumentality, perceptions of future, and connectedness). Instrumentality is how students' perceive present tasks as useful for their future. Perceptions of the future is the value a student places on a specific future goal, like becoming an engineer. Connectedness is the specific connections made between present tasks and future goals.

Prior research in engineering education links students' FTPs with self-regulated learning in post-secondary settings (Nelson, Shell, Husman, Fishman, \& Soh 2015), predicts student use of knowledge building strategies (Hilpert et al. 2012; Husman, Hilpert, \& Brem 2016), and positively influences students' problem solving strategies (Benson, Kirn, McGough, \& Faber 2015; Kirn \& Benson, 2018). Perceptions of the future, especially, has been linked to motivation to stay in an engineering degree pathway (Kirn \& Benson 2018). This framework provides an understanding of students' values and motivation in the present as linked to their future goals.

\section{Big Five Personality}

The Big Five personality dimensions capture five different personality traits: openness (open to change, new experience, imaginative, insightful); conscientiousness (reliable, hardworking, trustworthy, dependable, orderly, thorough); extraversion (sociable, talkative, impulsive, energetic, assertive); agreeableness (cooperative, helpful, likeable, sympathetic, kind); and neuroticism (anxiety, personal insecurity, tension, hostility, irritability; Judge et al. 1999). This framework for characterising personality has been studied extensively; researchers generally agree that the Big Five personality 
dimensions validity capture the structure and concepts of personality (Barrick \& Mount 1991). Personality is relatively stable, unlike other frameworks used in this study, and it has been shown to distinguish engineering students from other students (Scott and Sedlacek 1975). Among engineering students, personality distinguishes those students who choose particular engineering disciplines (Verdín, Godwin, Kirn, Benson, \& Potvin 2018) or degree pathways (Moses et al. 2011).

Additionally, personality has been shown to differentiate engineering students who persist from other students (Hall et al. 2015). Conscientiousness, especially, has been shown to influence engineering students' persistence in their degree paths and it is the most consistent predictor of the five dimensions of personality for academic success (Corker, Oswald, \& Donnellan, 2012; Noftle \& Robins 2007; O’Conner \& Paunonen, 2007; Vianello, Robusto, \& Anselmi 2010). High conscientiousness indicates a desire to do a task well, and to take obligations to others seriously (Barrick \& Mount, 1991). This personality trait is related to the types of goals, study strategies, and other academic behaviours that may indicate particular markers of individual differences for pathways upon graduation.

\section{Identity}

We define engineering role identity as the ways in which students describe themselves and are positioned by others in the role of being an engineer. This definition of identity is consistent with Gee (2001) who defined identity as, 'being recognised as a certain "kind of person," in a given context...' (p. 99). It is also consistent with the body of engineering education literature over the past two decades (Morelock 2017). Our definition of identity emphasises that recognition is both from an individual as well as important others (i.e., parents, instructors, peers) as individuals tell stories about who they are and act in congruence with these stories (Holland et al. 2001). 
In engineering education, identity development has been linked to many important outcomes including students' learning trajectories (Allie et al. 2009), belonging (Hughes 2010; Kraus 2006), motivation to learn and pursue engineering careers (Kajfez, Matusovich, \& Lee, 2016), choice of engineering in the transition from secondary to post-secondary education (Godwin, Potvin, Hazari, \& Lock, 2016), and persistence in engineering (Patrick, Borrego, \& Prybutok, 2018; Perez, Cromley, and Kaplan 2014; Pierrakos et al. 2009). Identity is a core aspect of individuals that informs their internal states as well as actions in the world; it has significant explanatory power in understanding student's career pathways.

We used Godwin's (2016) identity instrument to measure students' engineering identities in three dimensions: performance/competence beliefs (beliefs about one's ability to do well and understand engineering subject material and concepts), interest (engagement with the subject), and recognition (feelings that others see you as the kind

of person who can succeed). Interest is an important part of student identity as it drives decision-making and engagement with the subject (Renninger, Hidi, \& Krapp, 2014). Finally, students' feelings of recognition are internalised beliefs that others (i.e., peers, instructors, and parents) see them as the type of person who can do engineering work. These three constructs have been used in a number of studies in science, mathematics, and engineering education from secondary students to working industrial scientists. The history and development of these three constructs of identity are described in more detail in Potvin \& Hazari (2013).

\section{Social Cognitive Career Theory}

Social Cognitive Career Theory (SCCT) has been widely used to understand students' engineering decision-making and career pathways (Lent, Brown, and Hackett 1994, 2000). This framework examines how basic academic and career interests 
develop, educational and career choices are made, and academic and career success is obtained. It is particularly useful for our study because in addition to the personal attributes (e.g., personality) and attitudes (e.g., motivation and identity) SCCT also provides ways to better understand students' goals and expectations for their future careers. The theory incorporates a variety of concepts (e.g., interests, abilities, values, environmental factors) that appear in earlier career theories and have been found to affect career development. Students' outcome expectations or beliefs focus on the consequences or outcomes of performing particular behaviours. The choices that people make about the activities in which they will engage, and their effort and persistence at these activities, entail consideration of outcome as well as self-efficacy beliefs about their ability to succeed in those activities.

Much of the research using SCCT has been conducted in the U.S.; however, there are a growing number of studies that have used SCCT in other contexts. The majority were conducted in Asian (e.g., China and Taiwan) and European (e.g., Portugal, Germany, and Italy) countries and tested the interest/choice and satisfaction models in adolescent and university student samples enrolled in courses or degree programmes related to STEM fields (Sheu and Bordon 2017). Research from European countries did not produce consistent results in how students' beliefs about their abilities and goals influenced career outcomes and satisfaction. Additionally, many studies often excluded outcome expectations as a part of the models (Sheu \& Bordon 2017). In this study, we examine students' goals and outcome expectations to better understand their intentions to pursue an engineering pathway upon graduation in a U.K. context.

\section{Conceptual Framework}

Together, these four theoretical frameworks provide valuable insight into students' career pathways. We used multiple frameworks to provide complementary 
perspectives on individual differences among students that may affect the perceived fit and subsequent actions with particular occupational goals. Some of the frameworks used are areas in which insight can provide ways to better support students' development - identity and motivation. Others can indicate particular groups of students who may be more attracted to a career pathway in engineering industry—personality. Finally, SCCT provides a well-studied framing of how students' goals for future careers (outcome expectations) may shape their intentions to pursue particular pathways. These different theories are interconnected and provide a more holistic perspective in the measurement and analysis of how students' beliefs and personal attributes influence goal setting and behaviours.

\section{Sequential Explanatory Mixed Methods Study}

This paper describes a sequential, explanatory mixed methods study (Creswell and Plano Clark 2011). A mixed methods approach was taken to answer the research questions, which consist of both exploring what exists (RQ1 and RQ2; quantitative questions) and how students describe their experiences (RQ3; qualitative questions). These two streams of data give a general and rich picture of how students may make decisions to stay in or leave engineering after they graduate from their engineering degree programme. We sequentially collected the data (first quantitative data then qualitative data) and then mixed the two data streams in the analysis and interpretation of the findings. Below, we describe the quantitative methods and results and then the qualitative methods and results. Then, we describe the synthesis of these two streams of data in the discussion. We present the research this way to provide the results of the quantitative analysis before the qualitative information as the quantitative data informed the collection of the qualitative data in this study. 
Initially, a quantitative survey of students' attitudes and career goals, aligned with the conceptual framework for this study, was given to students in a two-week summer course titled, How to Change the World ( $\mathrm{HtCtW})$. The data from this survey were used to select interview participants. Participants were selected in a $2 \times 2$ design focusing on students who were strongly committed to either staying in or leaving their chosen university discipline upon graduation as well as students who were from the U.K./EU versus students who were from overseas. At the time of the study, tuition fees for U.K. and EU students in U.K. universities were the same and considerably lower than tuition fees for overseas students before the completion of the U.K.'s exit from the European Union. After the governmental change in affiliation, there are expected implications for future enrolment demographics. Recently, typical UCL Engineering Faculty cohorts have an approximately even split in U.K./EU and overseas students. All research activities were conducted within ethics guidelines at the institution.

\section{Study Context: HtCtW Course}

In the academic year 2014-15, UCL Engineering launched the Integrated Engineering Programme (IEP), an innovative teaching framework that intends to address its motto Change the World by identifying that 'to change the world, students need to be taught differently' (Sorensen 2016). The IEP teaching framework encompasses all students within UCL's Faculty of Engineering with the aim of producing engineers with an understanding of fundamental technical knowledge in a work-related context as well as a wide range of professional skills. This outcome is achieved through pedagogical approaches focused on multi-discipline and Scenariobased project learning in the context of research, which addresses real-life problems within global challenges or industrially relevant projects. 
This problem-based, interdisciplinary learning is immediately introduced to students in the first week of the first year of study at UCL, through one of two fiveweek team projects known as 'Challenges'; one is discipline specific and the other is interdisciplinary. After the Challenges, this scenario-style educationcontinues as Scenarios dispersed across the first two years as six, week-long, industrially relevant, mini-design projects in discipline specific teams. The focus of these Scenarios complements learning form other modules being taught concurrently. The culmination of the IEP after two years is the interdisciplinary, two-week intensive course $\mathrm{HtCtW}$ taken by all students within the Faculty of Engineering at the end of their second year, corresponding to 672 students in the year when this study was performed. A core teaching team of UCL academics, teaching or research staff and postgraduate teaching assistants develop and deliver multiple open-ended projects that address one of five global challenges such as water, energy, or transport. Further teaching material and support is provided by a wider team from the Science, Technology, Engineering and Public Policy (STEaPP) department, coordinators of the HtCtW course, and the Faculty of Engineering. Additionally, there is input and advice from public and private sectors, and charity organisations in preparation and delivery of the scenario style two-week intensive course, as well as two undergraduate teaching assistants supporting each core teaching team in the delivery of the course.

During the two weeks, students work in interdisciplinary teams of 5-6 individuals to address real-life, global challenges such as water problems in rural or over-populated areas in Asia, energy issues in global disaster spots and refugee camps or the concept of smart cities. Teaching and student support take the form of lectures, group workshops, and exercises and discussions with some input from external partners. 
The course culminates in a pitch and innovation showcase. Assessment is team-based and varied including a team video, pitch, and the innovation showcase itself.

It is within this context that the current student motivation study was performed. For further information on the IEP teaching framework and $\mathrm{HtCtW}$, see Sorensen (2016) and (Graham 2018). In the latter source, a report released by MIT School of Engineering, UCL Engineering has been identified as one of four emerging leaders in global engineering education, and thus, this context is particularly interesting for understanding students' pathways and career decisions in engineering.

\section{Quantitative Methods and Results}

\section{Sample}

During the $\mathrm{HtCtW}$ course, we administered an electronic survey instrument consisting of questions about students' current course of study, plans upon graduation, motivation in engineering, personality, engineering identities, outcome expectations, and demographic information. The electronic survey was sent to all students enrolled in the HtCtW course $(n=672)$. Students were offered a chance to be entered in a draw for one of two $£ 20$ Amazon Vouchers. A total of 128 students responded to the voluntary survey (19\% response rate). In comparison to the individual disciplines in which the Faculty of Engineering students on the $\mathrm{HtCtW}$ course were enrolled, the electronic survey responses were slightly overrepresented by chemical engineering and computer science students (Table 1). Mechanical engineering, school of management, and electrical and electronic engineering students were slightly underrepresented in their responses, while biochemical and biomedical engineering students responded at a similar rate to their enrolment in the course. For this study, we only used responses from engineering and computer science students in the sample. 
Table 1. Breakdown by department of student responses to the electronic survey and students enrolled in $\mathrm{HtCtW}$.

\section{Measurement}

Students indicated their engineering discipline and degree classification on the survey. They also responded to a question that asked them to, 'Please rate the likelihood of you choosing a career in each of the following fields.' Students were given eleven different options for future career pathways: Academia (Higher Education), Engineering Industry, Computer Science Industry, Entrepreneurship/Start a Company, Government/Policy, Law, Medicine/Health, Non-profit/NGO, Finance (i.e., City of London), Management Consultancy and Other. Students rated their likelihood of choosing a career in all of these options on an anchored numeric scale from 1-'Not at all likely' to 7-'Extremely likely'. The responses from this question were used to examine students' intentions to stay or leave their disciplinary pathway upon graduation. A normed index of likelihood of staying or leaving was created by examining students' highest responses on the eleven different career pathways.

If students' highest response on the eleven different careers was equal to or higher than the choice corresponding to their degree programme, they were assigned a 1 , and if not, they were assigned a -1 . The sum of all rankings across the possible disciplines was used to scale students' intended career pathways after graduation by both the absolute rating on the scale that corresponded to each of the eleven disciplines, as well as the relative rankings students gave other non-disciplinary related paths. This index was created to measure students who were strongly intending on leaving or staying as well as capturing students who were undecided in their choice. The scale was normed from -100 (extremely likely to leave) to 100 (extremely likely to stay) with 0 indicating students who were perfectly undecided (ranked all options with the same 
likelihood). For example, a student who was enrolled in a chemical engineering degree and marked a seven on engineering industry and a two on all other responses (indicating a likely choice of an engineering industry pathway upon graduation) would score 81.5. In comparison, a student who was enrolled in a chemical engineering degree and marked a two on engineering industry and a four on all other responses (indicating an undecided pathway but less likely to choose an engineering pathway upon graduation than other choices) would score -11.1. When we examined all student responses, we found a bimodal distribution of students who were intending on pursuing a degreerelated pathway upon graduation (Figure 1).

Figure 1. Histogram of the normed index of students' likelihood of choosing a career field consistent with their degree discipline.

\section{Analysis}

Because of the bimodal distribution of students' self-reported likelihood to remain in their disciplinary career path, we used a multinomial logistic regression (Anderson and Rutkowski 2007) to examine the predictive factors for being in the bottom tercile (leavers) and top tercile (stayers) versus middle tercile (undecided) in the same model. This statistical method allows for multiple categorical outcomes and allowed us to understand what made students more likely to be in the leave versus undecided group in comparison to the stay versus the undecided group. Therefore, we chose this method to compare the three different terciles of students' intentions simultaneously.

In this model, we controlled for demographic variables including students' selfreported race/ethnicity, gender, prior academic performance, and first-in-family status. To test for the influence of different attitudinal variables, we added-in each block of questions, in a stepwise fashion: controls and then the individual measures for theories 
in the conceptual framework. Adding in the demographic variables first allowed us to control for differences between groups in career intentions. Then, we added in our measurements for the four theories used - motivation (McGough, Kirn, and Benson 2016; Kirn and Benson 2015, 2013; Benson et al. 2016), outcome expectations for future careers (Klotz et al. 2014), personality (Judge et al. 1999; Kauffmann et al. 2008), identity (Godwin 2016), and reasons for choosing degree. Finally, we tested for an interaction effect between being from the United Kingdom/European Union versus being from overseas. All quantitative analyses were conducted in R: A Language and Environment for Statistical Computing (R Core Team 2018).

\section{Quantitative Results}

Our multinomial logistic regression revealed significant student attitudes that predicted the likelihood of students to be in the leaving or staying terciles in comparison to being in the undecided terciles. The results of the model are shown in Table 2.

\section{Students Who Intend to Stay in Engineering Career Paths}

The results from the multinomial logistic regression are logit estimates. The standardised estimates $(\beta)$ are the odds that the predicted variable (e.g., stay or leave, in comparison with undecided) will occur with a one-unit increase in the student attitude scale (Szumilas 2010). Students who intended to stay in their engineering degree paths upon graduation were more likely to have clear perceptions of the future $(\beta=12.987 ; p$ $<0.001)$. This result indicates that students who have a strong desire to be an engineer in the future are more motivated to pursue that pathway in the present. Of all the motivation constructs tested for this study, perceptions of the future was most closely tied to students' current and envisioned future selves and their goal setting and behaviours. This process of goal setting behaviour aligns with existing work in motivation (Raynor 1969) and self-concept (Markus and Nurius 1986; Oyserman 2004) 
that outline students with future goals or selves are more likely to set more proximal goals to reach their desired future or self. In general, the further a goal is from the present, the value of that goal decreases (Rachlin 1995). For students with strong perceptions of the future, this decrease in value over a longer temporal distance is less Table 2. Significant results for multinomial logistic regression of students' intentions to persist in degree to career path.

Note: $*=p<0.05 ; * *=p<0.01 ; * * *=p<0.001$

impactful on current goal setting. Students with longer perceptions of the future can also more easily anticipate the implications of their present activities for the more distant future and elaborate longer behavioural plans or projects. Our finding may have implications for how engineering students may be supported in developing motivations that increase intentions to persist in their degree to career pathway.

Students who intended to stay were less likely to want to supervise others than their undecided peers $(\beta=0.460 ; p<0.01)$. This result may be related to a trend specific to this U.K. institution that students want to enter finance within the City of London rather than enter engineering degrees. Students who intended to stay in engineering degree paths upon graduation may see supervising others as less important to their careers when compared to their peers.

These students were also less likely to have personality traits of conscientiousness $(\beta=0.342 ; p<0.05)$, agreeableness $(\beta=0.351 ; p<0.05)$, and openness $(\beta=0.313 ; p<0.01)$, than their undecided peers. Previous literature has shown that conscientiousness was the only personality trait of the Big Five measures predictive of engineering students' persistence (Atwood and Pretz 2016; Hall et al. 2015). These studies examined persistence in a degree programme rather than persistence in an engineering pathway upon graduation, which may account for the differences between our finding and prior findings. Other studies have shown that 
conscientiousness is one of the most significant predictors of grade point average (GPA) at university. Corker et al. (2012) described that association between conscientiousness and academic performance may be due to purposeful strategies including study strategies, work habits, and goals that promote academic success. In students' early academic pathways, Atwood and Pretz (2016) found that extraversion and agreeableness for engineering students were negatively correlated with academic performance. This relationship may help explain the negative estimate for agreeableness in our model. Extraversion was non-significant for students who planned to stay in engineering upon graduation. Finally, students who intended to stay had lower openness than their peers who were undecided. Openness is characterised by introspection, intellectual curiosity, and a willingness to entertain novel ideas, attributes loosely associated with creativity. Students further along in their engineering careers have a demonstrated decline in creativity (Atwood and Pretz 2016; Sola et al. 2017). Engineering education may reduce the likelihood of staying in engineering upon graduation for students whose personalities are higher in openness.

\section{Students Who Intend to Leave Engineering Career Paths}

Students who intended to leave engineering upon graduation were less likely to want a career that had hands-on work $(\beta=0.412 ; p<0.01)$. These students may have less well-defined perceptions of what an engineering job entails. Many members of the public perceive that engineers work in typical hands-on job sectors with the most commonly mentioned including construction, manufacturing, mechanics, cars, aeroplanes, trains, bridges, roads. Engineers were also described as 'fixing things' rather than engaging in design or problem solving (Marshall, McClymont, and Joyce 2007). Students who intended on leaving may not see themselves in the types of roles typically described as careers in engineering industry. 
These students also had differences in personality from those who were unsure of their intention to stay or leave. Students who intended to leave had higher openness $(\beta=3.438 ; p<0.01)$, lower extraversion $(\beta=0.445 ; p<0.05)$, and higher neuroticism $(\beta=1.978 ; p<0.05)$. Students who had the highest levels of openness in our study were most likely to leave. These results may be due to the reasons outlined above. Namely, engineering education often reduces creativity (Cooper, Altman, \& Garner 2002;

Cropley, 2015; Lumsdaine \& Lumsdaine, 1995) and students who desire careers that align with their personality may not see engineering industry careers as a viable option.

Finally, students who intended to leave were less likely to choose engineering because they felt that that pathway would guarantee them a job $(\beta=0.442 ; p<0.05)$. Because this is a cross-sectional study, we cannot infer causal reasons for this relationship. Students may not see engineering industry as a pathway that will guarantee them a job or they may not value getting a job as a reason for choosing or not choosing an engineering industry pathway. Our results do indicate that students who were more interested in an engineering industry pathway were less likely to have chosen their course of study because they believed an engineering degree would 'guarantee a job'.

\section{Overseas Students}

We found some significant differences for overseas students in comparison to their U.K./EU peers. Overseas students who were more conscientious were more likely to intend to leave engineering $(\beta=8.093 ; p<0.10)$. This result is in contrast to the main effect that students with higher conscientiousness were more likely to be undecided but not more likely to leave engineering. Conscientiousness may play a particular role in the context of this study for students and have an even larger effect on students' intentions to leave engineering for overseas students than their U.K./EU peers. Our results are an interesting contrast to the results of prior studies, often set in the U.S., 
which indicate that conscientiousness predicts higher academic performance and retention in engineering. This personality trait may have different effects within the engineering university and cultural context of this study.

Students' beliefs about their ability to understand engineering and do well in engineering courses (performance/competence beliefs) were a negative predictor of staying versus being undecided for overseas students $(\beta=0.228 ; p<0.05)$. Our finding may indicate that students who have higher beliefs about their abilities to succeed, especially those from overseas, may be more interested in other career pathways upon graduation. From a descriptive analysis of the data, we see that overseas students with high performance/competence beliefs were more likely to want to enter academia or medicine/health than their peers.

Our quantitative results indicate that there are patterns of students' attitudes, beliefs, identities that shape their desires and interest to continue in an engineering industry pathway upon graduation. While we can understand general trends from this analysis, we cannot understand how and why students indicate these responses. Our qualitative follow-up study with students provides additional details on students' decision-making processes.

\section{Qualitative Methods and Results}

\section{Sample}

Following electronic surveying, interviews were conducted to investigate trends in the quantitative results and to understand more deeply students' experiences that influence their intentions to stay in or leave their chosen engineering discipline (RQ3). Participants for interviews were selected after an initial analysis of the electronic survey results with the aim of interviewing a balanced selection of students who were representative of the demographics of the faculty's student population, including equal 
representation of U.K./EU and overseas students. Additionally, students' score on the normed index of likelihood to stay in their career pathway coupled with their indication of willingness to be interviewed was used to select interview candidates to represent an equal split of students who indicated their likelihood to persist in or leave their chosen discipline for their careers. All interviewed students were offered a £20 Amazon Voucher for participating in their 30-45 minute interviews.

\section{Interviews}

Two interviewers conducted 15 individual student interviews. There was a 53:47 split between stay and leave participants. It should be noted that categorising students' opinions as stay or leave is not as distinct as solely the interpretation of numerical results from the electronic survey. For example, a couple of students identified as leave in the electronic survey results gave an impression of being undecided based on interview responses, or considered careers which could be classed as stay. In terms of the splits between U.K./EU and overseas participants, a 67:33 split was represented, slightly skewed towards the U.K./EU group compared to the greater faculty.

The aim of the interview was to investigate further student motivation and reasoning for selecting their chosen university discipline, their current opinion and reasoning of why they envisioned themselves staying or leaving their chosen discipline. A semi-structured interview protocol was developed to ensure consistency between the two interviewers and across all interviews. Interviews were recorded and then transcribed to accurately capture the students' responses collected. The interviews were carried out within a week of completion of the electronic survey and during the twoweek $\mathrm{HtCtW}$ course. Students either chose or accepted their pseudonyms after the completion of the interviews. Table 3 shows participants' demographic information and pseudonyms. 
Table 3. Interview participant self-identified demographics.

* Career intention from survey classified this student as Leave but from the interviews they came across as stay or undecided.

\section{Analysis}

Following guidance on coding by Cohen, Manion, and Morrison (2013), an open coding method was used for initial coding of the interview data. To establish a baseline, each researcher coded the data in vivo to capture the essence of the transcript in students' own words. Next, the authors developed an axial coding scheme through discussion and consensus of the main themes present in the transcript. This coding scheme, presented in Table 4, was used to consistently code the data across the researchers.

Table 4. Codes developed inductively by the research team during analysis.

\section{Qualitative Results}

The qualitative portion of our study gave voice to students' descriptions of why they were interested in staying in or leaving an engineering career pathway. We found the students who had expectations that were aligned with the work being done in their chosen engineering discipline were more inclined to want to stay in their discipline. Students' experiences also provided critical incidents that they discussed as reasons, sometimes leading to decision points, for their intentions to stay in or leave engineering upon graduation. Students discussed parents and having specific qualifications most often for influences that might have caused them to choose or stay in engineering. Finally, students most often described a sense of belonging within engineering at university as a reason for intending to stay in engineering. While some students discussed their confidence in completing engineering subjects, most students focused on belonging as a main affective reason for intending to stay. 


\section{Expectations}

From the general trends students who had a good understanding or appreciation of their chosen discipline were significantly more inclined to stay in their discipline upon graduation based on how students described their expectations of engineering and the influence that these expectations had on their intentions to stay. For example, when reflecting on what they had already learned at university in their first two years of study in their chosen discipline students shared,

...The second year has developed a lot more into the specifics of the discipline...I'm really happy about second year. (Paul)

...I mean there are subjects, modules, that I don't think relate to what I want to do but even then, they give me ideas of what I can do in the other modules. (Jade)

Furthermore, an understanding of the skills required within a chosen discipline reinforced students' intentions to stay within their chosen discipline, as reflected upon by one student,

...I'm confident in my abilities and all my skills that I've acquired until now...I know that I [am] fit to work in the field on the actual jobs that I will have... (Scott).

On the other hand, students who had a misunderstanding of their engineering discipline and the skills that form part of the learning in their chosen discipline were less likely to indicate that they were planning on staying in engineering upon graduation. When reflecting on her understanding of the skills involved in her chosen discipline whilst still at school, compared to her then current knowledge at the end of the second year, one student shared,'I thought it was a lot of chemistry and maths, but it's actually more about physics and maths. So, it was a bit different than what I thought' (Mona). While others showed a misunderstanding of the wider skills gained as part of an engineering degree and did not see particular foci of the programme like 
communication and teamwork as 'engineering enough'. When asked how confident John was in his chosen discipline he reflected on the wider skills gained at university and said,

It fluctuates. First year, I didn't do anything. I wasn't very motivated, because I thought I was just going to do science. It turns out engineering involved so much soft skills, especially [at] UCL, that it demotivated me. I didn't do much in [my] first year. I ended up repeating it, because I have two modules to do. This is actually my second year, so I should be in third year right now. Yeah, I found it demotivating how much soft skills we're doing... (John)

Our results are consistent with prior work that shows that students' current motivation and intentions to persist in engineering are tied to their future goals and the quantitative results showing perceptions of future as particularly important for intentions to stay in engineering career pathways.

Students can feel that studying their chosen discipline has contributed to their development despite not seeing their chosen discipline as a potential pathway for their career. One student Kelly Baker shared,

...I still enjoy learning it, it's just that I don't see myself doing [engineering] for a career, for the rest of my life.

When probed further about her decision, Kelly Baker shared

...Just the idea of having to do [engineering] every day for the rest of my life just kind of puts me off. I think it's also the fact that I have alternatives now...

She went onto to discuss her experience of a chemical engineering internship and the UCL Global Citizenship Programme and that she was more interested in using her knowledge of engineering in public policy.

Another student, Priya, also discussed a general interest in the subject, but the inability to see engineering as a career. When asked about her confidence in her chosen discipline she shared, 
I'm confident that it was the right decision when I picked it, but I'm finished my second year of university, so I'm in two minds as to whether I want to go into chemical engineering when I finish. I'm looking into it now. I' $m$ in the process of looking for jobs to apply and things like that, but I don't know if they will be engineering related. I do enjoy the content, but I'm not sure if I have the passion, the drive for it to go into a full career within engineering, if that makes sense....I'm really glad I chose it because I learned a lot, but I don't think it's gonna be the best thing for me as a career.... At the moment, I'm looking at consulting, but that is literally the first thing I'm looking at. I'm still trying to work out what is out there and what will suit me, and my personality, and my skills that I have from studying engineering.

As these quotes indicate, while both women were considering leaving engineering, they found their studies as valuable for their next steps. Students did not necessarily view switching fields after university as a negative outcome. This finding is consistent with research that shows that women navigate their engineering pathways differently than their male peers (Hatmaker 2013). Women more often have to negotiate their developing identities as engineers along with their gender identity within a masculine engineering culture. Other work has shown that while women persist at the same rate as men within university (Ohland et al. 2008), they often do not enter the engineering workforce at the same rates (Burke and Mattis 2007).

Prior work has demonstrated the importance of students' expectations of engineering in retention. Besterfield-Sacre et al. (1997) found that students who thought highly of engineering as a field had a higher first-year retention rate. More recent work has demonstrated that interest and a perceived fit within engineering as a future career is a key part of students' decisions to stay in or leave engineering (Geisinger and Raman 2013). Grandy (1998) showed that student interest was more predictive of student retention in university than grades. Most students leaving engineering reported that other career pathways were more appealing than engineering rather than leaving for 
other reasons (Seymour and Hewitt 1997). Our results support prior findings, and examine students' expectations about engineering and the congruency of these expectations with their own identities and interests as engineers in a U.K. context, where it may be more difficult to identify as an 'engineer' based on cultural norms of engineers not only including bachelor degree holders but also anyone who builds or fixes things.

\section{Experiences and Influencers}

We found that students' expectations of engineering curriculum and careers were not the only major reasons students intended to stay in or leave engineering upon graduation. Students' experiences within engineering during their undergraduate education were significant shaping forces for their intentions. Students also described influencers, especially parents, who supported their intentions to stay in or leave engineering upon graduation as important to their personal journeys.

Closer inspection of the experience code indicated that the top three contributing experiences were university experiences, school experiences prior to university, and work experiences in a student's chosen discipline. However, analysis of the transcripts indicated that it is overwhelmingly the experiences which students have at university that contribute to their decision to stay or leave their discipline upon graduation. This finding suggests that educators have a significant responsibility to ensure that a student's experience related to their discipline is positive, and so can encourage students to stay within their chosen field.

When reflecting back on his course over the first two years Scott described his experience, not only the challenges but also the enjoyment, on one of the IEP Scenarios, which are completed in the first two years of the IEP prior to taking the $\mathrm{HtCtW}$ course as: 
One [Scenario] we had that as a team to assemble robots and activating them around. I actually work with the other guy the same team and really had enjoyed working for it. I mean it was the only Scenario week I went to sleep in the night, I woke up started working on it till the night, went to sleep again the whole week and I enjoyed working on it. It was about some obstacles and robots going between them based on subordinate. ...I enjoyed it, it wasn't only about the grade or it's also about experience in what we learn. (Scott)

The project-based learning that students gained through the IEP Scenarios was overwhelmingly popular with the majority of interviewees (thirteen out of fifteen) who discussed positive comments with regard to the IEP Scenarios irrespective of their overall viewpoint to stay or leave engineering.

The students' positive view of team/group-based project coursework, which reflects an important element of engineering practice in the workplace, contributed to the formation of a positive attitude to stay for some students. This finding connects to our quantitative results that indicate that students with stronger perceptions of the future are more likely to stay in engineering upon graduation. Students who were able to see how current activities connected to their future goals (instrumentality of experiences and the ability to project into the future) described experiences that are more positive. When one student was asked what part of her education she saw as relevant to her future, she shared:

...I can appreciate the way [projects] help us to work in a group even if we don't like the people in that group. And just, you know, being able to reach deadlines when you have other people to worry about, I think that's a really necessary skill for later on. (Jade)

When Paul was asked what his most challenging experience had been, he reflected on the challenges of group work but also the benefits of practising other skills as a result of challenges encountered in group work and shared: 
...Working with some of the people was very challenging. They wouldn't show up, they wouldn't do any of the work and yet you have to find some way of cooperating with them. I guess it was the up and down because it's going to make the experience more rewarding when you found out you did really well managing difficult people but it was really challenging at points as well. (Paul)

It is important to note that even amongst students who indicated an inclination to leave their chosen discipline, the ability to make some connection as to what the future would be in their chosen field of study was important, as one student shared:

...So, it was an interesting topic and we'd gotten to actually go to an ice cream, I don't know if it's an ice cream factory, it's a factory where they make ice cream. So, it was good to actually see the pilot plant and stuff and then relate that to what we were doing. That was probably the most enjoyable. (Steve)

In fact, except for a desire for more high-quality feedback on papers and assignments, the only code under the teaching method theme that had more negative than positive comments was the traditional university teaching method of lectures. This finding may be an aspect that educators have always encountered. However, the reasons students have negative viewpoints on lectures were wide-ranging from lack of motivation to confusion and frustration on lecture material content or desire for more interactive learning:

...it's not about waking up because I'm not that person, I wake up early in the morning. It's just that I lack motivation to go to lectures... (Scott)

I feel that the lectures could be better, people end up just skipping them learning it by themselves, because they're just not ... there's a lot of stuff just stuffed into one lecture. We don't know what's useless, what will we ever use, what should we learn for the exam, what will even be in the exam, so people just don't really connect with the lectures...but again, if I just know the science and I don't know how to apply it there's no point to it... (John) 
What would help me learn? Like a more interactive way for me. Instead of lectures, we can have like field trips as well and maybe a model would really help, like modelling... a real model that would present how it actually works instead of just telling us the theory of it, but we really see how it works. I think that would be more exciting and we would learn more from it. (WW)

Lectures as a form of instruction have been repeatedly shown to be less effective than collaborative and active learning strategies in reviews of the literature and a metaanalysis examining the effect sizes of different teaching strategies for student learning (S. Freeman et al. 2014; Prince 2004). However, despite the growing evidence for using more collaborative and active strategies in the classroom, lectures remain the predominant form of education (Kelly 2012). As already discussed in this work, university experiences are a significant contributing factor leading students to decide to stay or leave their chosen discipline.

Most students described positive influences when examining the Influencers code. We note that the Influencer code was used much less frequently than that of the Experience and Expectation codes in our analysis. It is also interesting that some students credited themselves most often as the Influencer in their decision-making process, exemplified by the following quote from Marc when asked about how he chose his discipline, 'I wasn't really led down any path, I was just kind of left on my own and made my own decisions.'

Most students who did describe influencers cited parents and other family members as important in their decisions to stay in engineering. Students, who had engineering parents or who were aware of engineering as a valuable field of study, more often reported that their parents supported their decision to pursue an engineering degree. For example, Doug shared, 
My parents liked the idea of engineering. My mom thought I would be better suited at something more hands-on than just sitting there in maths all day.

While students reported a variety of influences on their decisions including family, university faculty or staff, university website or literature, and secondary teachers, the most common influencer reported was family. This finding is consistent with prior literature that shows that students with family members in engineering, especially parents, siblings, and other relatives are more likely to choose engineering careers (Godwin, Potvin, and Hazari 2014). Families are critical to providing support for student attainment through emotional as well as financial dimensions, from purchasing textbooks to paying for university (Teachman and Paasch 1998; Seginer 2006). Parents shape their children's attitudes, motivations, values, and aspirations through a socialised family culture and are a locus of control in the education of their children (Dorie and Cardella 2013; Dryler 1998).

\section{Confidence}

We found that students' feelings of belonging were most important in both saliency and frequency for students' future career intentions based on students' descriptions of the reasons for their confidence, or lack thereof, in their future engineering pathway. For example, Alison, when recounting a story from her engineering department concluded with the comment, '...[Quick replies to emails] just helps so much. It makes you feel part of the department, everything like that...' Many students who intended to stay in engineering, like Alison, reported social connections within their department, especially with academics, as important for feeling like they belonged.

Other students described belonging in terms of their ability to do the work required for the degree programme and finding enjoyment or fulfilment in the projects. For example, Matt shared, 
Just mainly because it's something I've been interested in for a while... so I just naturally feel like that helps me to fit in. That's the one thing that unites any computer scientist is a craving to learn more about the world, about computers and actually use what they learn to solve problems.

Another student, WW did say that she would like a job in chemical engineering; however, she also shared that she would not see herself as a chemical engineer until she earned her degree and the knowledge and confidence to do a project by herself. When asked if she felt she belonged WW acknowledged she did and again linked this feeling to confidence by sharing,

I could tackle most of the questions, it's just that in projects ... and working on programs that I'm not so confident in it, but in other cases I am very confident in myself.

Another student who intended to leave engineering described that she did not feel like she belonged in her field, although her feeling of belongingness was different within the university and industry context. When asked if she was planning on working in chemical engineering when she finished Priya initially said 'No, I don't think so. I mean I have to see how my next year of studying goes, but no.' Later in the interview when asked if she saw herself as a chemical engineer she responded, 'I see myself becoming a chemical engineer. Regardless of whether I go into the career or not, I think by having the degree I am, essentially one. Yeah.' Finally, when asked if she felt like she belonged in chemical engineering she considered university and industry settings differently and responded, 'At university, yes. In industry, or as a career, I don't know if I'd feel that way.' This set of questions indicates Priya's struggle with deciding if a chemical engineering industry career was something she wanted to pursue. Her survey results indicated that she intended on leaving an industry pathway upon graduation but her interview revealed more nuanced insight into her feelings about chemical engineering as a course of study versus a career. 
This response indicates the importance that a sense of belonging brings to students in forming opinions about their chosen discipline and equally how their perception of belongingness can change depending on the setting, be it university or industry. Belonging focuses on establishing membership and connectedness within a student's institution, within their chosen discipline and the links they can create with potential future industry employers.

A lack of belongingness has been identified as one of the top reasons that students leave a university (Geisinger and Raman 2013; Marra et al. 2009). Belongingness is an essential part of a student's educational experience, at both the classroom and university levels (T. M. Freeman, Anderman, and Jensen 2007; Wilson et al. 2015). Prior work has also found that beliefs about seeing oneself as the type of person who can be an engineer had a positive effect on students' sense of belonging in the engineering field and classroom (Verdín et al. 2018). Students most often describe belongingness as a feeling of comfort, specific skills or attitudes they possessed that fit with their degree programme, or enjoyment of their subject (Rohde et al. 2018). Our results indicate that belongingness plays an essential role in students' decision making, consistent with prior literature, and that belonging may be fostered through creating connections between students and their peers as well as academic connections within the institution. Confidence with subject material and enjoyment may be particular areas of future work in promoting student belonging. Furthermore, this work indicates that belongingness needs to be fostered for a career pathway into an industrial context so that a feeling of belonging created within a university context is not lost as students graduate and are ready to embark on careers in industry. 


\section{Discussion}

In this mixed methods study, our quantitative data collection and analysis informed the selection of participants in the qualitative portion of the study. In this approach, the qualitative data can provide richer insights into the trends found from quantitative data (Johnson and Onwuegbuzie 2004).

From our quantitative results, we found that students' perceptions of the future, or their beliefs about their future goals and how far an individual projects those thoughts, was the strongest predictor of intentions to pursue a career in engineering industry upon graduation. The probability of students indicating that they planned to stay in an engineering career pathway was $92.9 \%$ greater when students had higher perceptions of future. We also found that students who were more open were less likely to stay in engineering careers ( $23.8 \%$ less likely) and more likely to leave engineering careers (77.5\% more likely). Conscientiousness was also a negative predictor of staying when compared to being undecided (25.5\% less likely), but for overseas students, higher conscientiousness was significantly predictive of intentions to leave $(89.0 \%$ more likely). These findings indicate that students' motivation, as connected to their future career goals, is more important than other attitudinal factors or background characteristics.

Students' personalities also predicted their intentions, with differential effects for overseas students. This finding may indicate that engineering education in this university context may not be perceived by students as congruent with students' attitudes that are more creative, flexible, curious, and adventurous as well as for overseas students with an orientation towards organisation, purposeful action, selfdiscipline, and a drive to achieve. 
This result is noteworthy because the UCL Faculty of Engineering systematically employs education research-based curriculum delivery that is targeted to inspire and encourage creative and innovative engineering solutions. Several factors may be influencing this finding. One possible factor is that engineering students might not have the teamwork and professional skills necessary to focus on creativity rather than overcoming interpersonal conflict in teamwork. This dynamic may be especially true when students are placed in inter-disciplinary teams without a history of shared ways of working. Additionally, engineering education projects often focus on getting to the results rather than the creative process of design (Rodríguez-Simmonds et al. 2017). This focus could suppress the creative process. Finally, typical tight deadlines for project delivery of conceptually new material for students could be a barrier that combined with the above factors could lead these students to feel stifled from expressing their creative nature, ultimately discouraging their future self-perception in engineering careers.

Our qualitative results give depth to some of the trends from the quantitative results. Students' who had a clearer understanding of the skills sets and expectations of their role as an engineer in their discipline were more likely to stay. The students who described leaving engineering career pathways upon graduation, more often referred to a misalignment in expectations or an inability to see themselves in those roles in the future. Our results indicate a need to communicate clearly not only what engineers learn at university but also possibilities of what their role will be in their careers and society. Student experiences at university overwhelmingly contributed to their decision to stay or leave. Providing opportunities to connect future careers to current coursework may increase students' connectedness attitudes. This approach may also increase students' 
extension of the utility of a degree beyond just the point of graduation and into a future career.

An important finding was the mode of teaching at the university had a significant influence on students' future intentions. Lectures were often cited as full of information that students struggled to sift through compounded with uncertainty as to what would be important for their future careers. Students discussed being demotivated by lectures and described a stronger desire to apply the concepts they were learning in 'real-life contexts'. Students also described how valuable industry experiences were to their interest and motivation for a future career in engineering.

The emergent themes of teaching methods and experiences added to our understanding of what may be influencing students' attitudes that were important for staying or leaving in the quantitative results. Teaching methods that mirror project work that will be done in future engineering roles are very positive and can help support more traditional methods such as lectures. We do not suggest the removal of lectures from the university experience. Lecturing can be a useful way to convey information. Instead, we encourage instructors to investigate innovative methods that can be employed within a lecture environment such as flipped lectures, student involvement through interactive quizzes and incorporation of lecture material within the context of project work such as is the case in the IEP Scenarios. These approaches not only strengthen students' learning as indicated by repeated research (Freeman et al. 2014; Prince 2004) but may also improve their motivation in their coursework and strengthen intentions to enter the engineering workforce upon graduation. It is important to point out that the $\mathrm{HtCtW}$ course context was generally perceived by students to meet these needs; however, some students felt that the experiences of this two-week course were not always the same as their coursework throughout the rest of the programme. 
Finally, students' feelings of belonging not only at the university but also in the field of engineering were important for their intentions to stay in or leave engineering. Most students felt like they belonged at university. However, some students indicated that they felt they did not belong in engineering industry. This finding may illustrate a facet of why students who were originally interested in engineering careers upon entering the university may not want to continue in their degree pathway. Students' descriptions of why they did not belong in industry - either a lack of interest, connectedness, or confidence in their abilities to succeed — are similar to prior work that found that positive engineering task and outcome expectations predicted positive job attitudes, which was a negative predictor of turnover intentions (Singh et al. 2013). Our results highlight that trends found for individuals' intentions to leave engineering industry once in the workforce may also apply to students earlier on in their careers.

We acknowledge that students deciding to leave their degree discipline is not necessarily negative. Many engineers, after gaining a few years of design or operational experience, will branch out into project management, commercial, management or financial roles; this work merely indicates that some students are making this decision sooner in their pathways without the initial experiences in engineering industry that may shape better-informed decisions. Efforts to support students' engagement with and exploration of engineering industry careers may be useful to help them make decisions about their pathways.

For students who have negative experiences that shape pathways, different efforts can be made. Students who encounter lecture heavy, personally difficult coursework, may have different experiences from what they imagined engineering would entail during university and beyond, or a lack of perceived fit or belonging within engineering industry based on brief experience and misinformed expectations. Based on 
our findings, we suggest supporting students' motivation, especially clearer perceptions of what a future engineering career would involve and how their current education in class connects to that future.

\section{Limitations and Future Work}

This study is a starting exploration of students', intentions to stay in or leave engineering career pathways after graduation, in one U.K. engineering programme. We acknowledge that this study is limited in its generalisability to a larger population. Our results do indicate some particular areas for supporting students, including making engineering career decisions clearer before entering university to align students' expectations with the coursework required for the degree programme, moving away from just lectures to other types of instruction, and providing opportunities for students to envision futures that include them in an engineering career without requiring an internship. These results provide additional insight into this particular context and provide specific leverage points that are different than prior studies of students' intentions in the U.S. context.

The mixed methods approach of both understanding general trends in the data and more deeply exploring students' experiences is a strength of this work; however, there were some instances where the results of the quantitative work did not align with student interviews. For example, two students indicated an intention to leave engineering upon graduation on their surveys, but in the interviews, their decision was less firm. In the survey data, they had indicated some other career pathway as higher than their interest in an engineering career, resulting in a negative score in the intention to stay index. This result indicates challenges of both quantitative measurements in fully capturing students' decisions as well as the nuanced discussions provided in the qualitative interviews used in this research. Our future work will continue to refine how 
we measure students' intentions to better understand how to capture this nuanced outcome.

Our future work will also more deeply investigate stories within the qualitative data. In this work, our focus was to synthesise findings across the quantitative and qualitative data streams. We plan to examine the theme of decision points to better understand how students form these decisions in context and draw similarities among the students who intend to leave engineering versus those that intend to stay.

\section{Conclusions}

This study examined UCL students' intentions to stay in or leave engineering career pathways upon graduation. We found that students' perceptions of the future, a motivation construct, was the strongest predictor of students' intentions to stay in engineering. Additionally, students with higher openness scores were more likely to leave engineering. We also found differences in overseas students' beliefs about their ability to do engineering work and a higher likelihood to leave engineering. The interview data added additional context to some of these trends. If students had clear expectations of what an engineering degree programme and career would be and those expectations were aligned with their experiences at university, they were more inclined to stay. Students also indicated a desire to have more practical or hands-on experiences in their education rather than just focusing on technical content in lectures. Finally, students described experiences of belonging within their degree programme but expressed doubts about a fit with an engineering industry career. These results provide ways that students may be supported in choosing engineering careers after graduation. Specifically focusing on students' connection of goal-setting with future career pathways, setting clear expectations for what a university experience and future career pathway in engineering industry entails through career exploration, and creating 
classroom experiences that support hands-on and active learning opportunities rather than lecture may be particular ways to help students see engineering industry careers as possible pathways for them. Our findings also add new insights into reasons why the United Kingdom has particular challenges in developing engineers who enter the workforce and may provide some ways to begin addressing that challenge.

\section{Acknowledgements}

The authors would like to thank the UCL Global Engagement Office and UCL Department of Chemical Engineering as well as the National Science Foundation (1626287) for funding parts of this work. The authors would also like to thank the anonymous participants for their time and the organisers of the How to Change the World course.

\section{References}

Allie, Saalih, Mogamat Noor Armien, Nicolette Burgoyne, Jennifer M. Case, Brandon I. Collier-Reed, Tracy S. Craig, Andrew Deacon et al. "Learning as acquiring a discursive identity through participation in a community: Improving student learning in engineering education." European Journal of Engineering Education 34, no. 4 (2009): 359-367.

Anderson, Carolyn J, and Leslie Rutkowski. 2007. "Multinomial Logistic Regression." Best Practices in Quantitative Methods, 390-409.

Atwood, Sara A, and Jean E Pretz. 2016. "Creativity as a Factor in Persistence and Academic Achievement of Engineering Undergraduates." Journal of Engineering Education 105 (4): 540-59.

Barrick, Murray R, and Michael K Mount. "The big five personality dimensions and job performance: A meta- analysis." Personnel psychology, 44, no. 1 (1991): 1-26.

Benson, Lisa, Adam Kirn, and Courtney J Faber. "Career: Student motivation and learning in engineering." In 2014 ASEE Annual Conference \& Exposition, pp. 24-261. 2014. 
Benson, Lisa, Catherine McGough, Justine Chasmar, and Adam Kirn. 2016. "CAREER: Informing Instructional Practice through the Study of Students' Future Time Perspectives.” In American Society for Engineering Education Annual Conference \& Exposition. New Orleans, LA.

Benson, Lisa, Adam Kirn, Catherine McGough, and Courtney J Faber. "CAREER: Students' Perceptions of Problem Solving Driven by Motivations Across Time Scales." In 2015 ASEE Annual Conference \& Exposition, pp. 1-5. 2015.

Besterfield-Sacre, Mary, Cynthia J Atman, and Larry J Shuman. 1997. "Characteristics of Freshman Engineering Students: Models for Determining Student Attrition and Success in Engineering.” Journal of Engineering Education. 86 (April): 139-49.

Brown, Philip R., Rachel E. McCord, Holly M. Matusovich, and Rachel L. Kajfez. "The use of motivation theory in engineering education research: a systematic review of literature." European Journal of Engineering Education 40, no. 2 (2015): 186-205.

Burke, Ronald J, and Mary C Mattis. 2007. Women and Minorities in Science, Technology, Engineering, and Mathematics: Upping the Numbers. Edward Elgar Publishing.

Cohen, Louis, Lawrence Manion, and Keith Morrison. 2013. Research Methods in Education. Routledge.

Cooper, C., W. Altman, and A. Garner. "Inventing for business success." Texere: New York (2002).

Corker, Katherine S, Frederick L Oswald, and M Brent Donnellan. 2012. "Conscientiousness in the Classroom: A Process Explanation." Journal of Personality 80 (4): 995-1028.

Creswell, John W, and V L Plano Clark. 2011. "Choosing a Mixed Methods Design.” In Designing and Conducting Mixed Methods Research, 53-106.

Cropley, David H. "Promoting creativity and innovation in engineering education." Psychology of Aesthetics, Creativity, and the Arts 9, no. 2 (2015): 161.

Dorie, Brianna L., and Monica E. Cardella. 2013. "Engineering Childhood: Knowledge Transmission Through Parenting.” In American Society for Engineering Education Annual Conference \& Exposition. Atlanta, GA. 
Downey, Gary Lee, and Juan C Lucena. 2005. "National Identities in Multinational Worlds: Engineers and Engineering Cultures'.” International Journal of Continuing Engineering Education and Life Long Learning 15 (3-6): 252-60.

Dryler, H. 1998. "Parental Role Models, Gender and Educational Choice.” British Journal of Sociology, 49 (3): 375-98.

EngineeringUK. 2017. "Engineering UK 2017: Synopsis and Recommendations.” https://www.engineeringuk.com/media/1355/enguk-report-2017.pdf. Accessed 25 January 2019.

_. 2018. "Engineering UK 2018: Synopsis and Recommendations." https://www.engineeringuk.com/media/1576/7444_enguk18_synopsis_standalon e_aw.pdf. Accessed 23 January 2019.

Francis, Becky, Louise Archer, Julie Moote, Jen DeWitt, Emily MacLeod, and Lucy Yeomans. 2017. "The Construction of Physics as a Quintessentially Masculine Subject: Young People's Perceptions of Gender Issues in Access to Physics." Sex Roles 76 (3-4): 156-74.

Freeman, S, S L Eddy, M McDonough, M K Smith, N Okoroafor, H Jordt, and M P Wenderoth. 2014. "Active Learning Increases Student Performance in Science, Engineering, and Mathematics." Proceedings of the National Academy of Sciences 111 (23): 8410-15. https://doi.org/10.1073/pnas.1319030111.

Freeman, Tierra M, Lynley H Anderman, and Jane M Jensen. 2007. "Sense of Belonging in College Freshmen at the Classroom and Campus Levels.” The Journal of Experimental Education 75 (3): 203-20.

Garibay, Juan C, Bryce E Hughes, M Kevin Eagan, and Sylvia Hurtado. 2013. "Beyond the Bachelor's: What Influences STEM Post-Baccalaureate Pathways." In Association for Institutional Research Annual Forum, Long Beach, CA, USA, May, 18-22.

Gee, James Paul. 2001. "Education Identity as an Analytic Lens for Research.” Review of Research in Education 25: 99-125.

Geisinger, Brandi N., and DR Raj Raman. 2013. "Why They Leave: Understanding Student Attrition from Engineering Majors.” International Journal of Engineering Education 29 (4): 914-25. 
Godwin, Allison. 2016. "The Development of a Measure of Engineering Identity." In Proceedings from ASEE 2016: American Society for Engineering Education Annual Conference \& Exposition, 15. New Orleans, LA.

Godwin, Allison, Geoff Potvin, and Zahra Hazari. 2014. "Do Engineers Beget Engineers? Exploring Connections Between the Engineering-Related Career Choices of Students and Their Families." In American Society for Engineering Education Annual Conference \& Exposition, 16. Indianapolis, IN: ASEE. Godwin, Allison, Geoff Potvin, Zahra Hazari, and Robynne Lock. 2016. "Identity, Critical Agency, and Engineering: An Affective Model for Predicting Engineering as a Career Choice." Journal of Engineering Education 105 (2): 312-40. https://doi.org/10.1002/jee.20118.

Graham, Ruth. 2018. "The Global State of the Art in Engineering Education.” Massachusetts Institute of Technology (MIT), Massachusetts, USA2018.

Grandy, Jerilee. 1998. "Persistence in Science of High-Ability Minority Students:

Results of a Longitudinal Study." The Journal of Higher Education 69 (6): 589620.

Hall, Cathy W, Paul J Kauffmann, Karl L Wuensch, William E Swart, Karen A DeUrquidi, O Hayden Griffin, and C Steve Duncan. 2015. "Aptitude and Personality Traits in Retention of Engineering Students." Journal of Engineering Education 104 (2): 167-88.

Hatmaker, Deneen M. 2013. "Engineering Identity: Gender and Professional Identity Negotiation among Women Engineers." Gender, Work \& Organization 20 (4): 382-96. https://doi.org/10.1111/j.1468-0432.2012.00589.x.

Hilpert, Jonathan C., Jenefer Husman, Glenda S. Stump, Wonsik Kim, WEN- TING

CHUNG, and Mary Anne Duggan. "Examining students' future time perspective: Pathways to knowledge building 1.” Japanese Psychological Research 54, no. 3 (2012): 229-240.

Holland, Dorothy, William Jr. Lachicotte, Debra Skinner, and Carole Cain. 2001. Identity and Agency in Cultural Worlds. Havard University Press.

Hughes, Gwyneth. 2010. "Identity and Belonging in Social Learning Groups: The Importance of Distinguishing Social, Operational and Knowledge-Related Identity Congruence.” British Educational Research Journal 36 (1): 47-63. 
Humphries-Smith, Tania, and Clive Hunt. 2017. “An Exploration of Progression Rates of Widening Participation Students on to an Integrated Master of Engineering." International Journal of Higher Education 6 (4): 69.

Husman, Jenefer, Jonathan C. Hilpert, and Sarah K. Brem. "Future time perspective connectedness to a career: the contextual effects of classroom knowledge building." Psychologica Belgica 56, no. 3 (2016): 210.

Husman, Jenefer, and Duane F. Shell. "Beliefs and perceptions about the future: A measurement of future time perspective." Learning and Individual Differences 18, no. 2 (2008): 166-175.

Imenda, Sitwala. "Is there a conceptual difference between theoretical and conceptual frameworks?” Journal of Social Sciences 38, no. 2 (2014): 185-195.

Johnson, R. Burke, and Anthony J. Onwuegbuzie. 2004. "Mixed Methods Research: A Research Paradigm Whose Time Has Come.” Educational Researcher 33 (7): $14-26$.

Judge, Timothy A, Chad A Higgins, Carl J Thoresen, and Murray R Barrick. 1999. “The Big Five Personality Traits, General Mental Ability, and Career Success across the Life Span.” Personnel Psychology 52 (3): 621-52.

Kauffmann, P, Cathy Hall, Gene Dixon, and John Garner. 2008. "Predicting Academic Success for First Semester Engineering Students Using Personality Trait Indicators." In 2008 Conference Proceedings of the American Society of Engineering Education, Pittsburgh.

Kelly, Gabrielle E. 2012. "Lecture Attendance Rates at University and Related Factors." Journal of Further and Higher Education 36 (1): 17-40.

Kirn, Adam, and Lisa Benson. 2013. "Quantitative Assessment of Student Motivation to Characterize Differences between Engineering Majors.” In Frontiers in Education Conference, 2013 IEEE, 69-74. Oklahoma City, OK.

—. 2015. "Engineering Students' Perceptions of the Future: Exploratory Instrument Development." In American Society for Engineering Education Annual Conference \& Exposition, 14. Seattle, WA. https://peer.asee.org/23979. . "Engineering students' perceptions of problem solving and their future.” Journal of engineering education 107, no. 1 (2018): 87-112.

Klotz, Leidy, Geoff Potvin, Allison Godwin, Jennifer Cribbs, Zahra Hazari, and Nicole Barclay. 2014. "Sustainability as a Route to Broadening Participation in 
Engineering.” Journal of Engineering Education 103 (1): 137-53.

https://doi.org/10.1002/jee.20034.

Kraus, Wolfgang. 2006. "The Narrative Negotiation of Identity and Belonging.”

Narrative Inquiry 16 (1): 103-11.

Lent, Robert W., Steven D. Brown, and Gail Hackett. 1994. “Toward a Unifying Social Cognitive Theory of Career and Academic Interest, Choice, and Performance." Journal of Vocational Behavior 45 (1): 79-122.

— 2000. "Contextual Supports and Barriers to Career Choice: A Social Cognitive Analysis." Journal of Counseling Psychology 47 (1): 36-49. https://doi.org/10.1037//0022-0167.47.1.36.

Lichtenstein, Gary, Heidi G Loshbaugh, Brittany Claar, Helen L Chen, Kristyn Jackson, and Sheri D Sheppard. 2009. “An Engineering Major Does Not (Necessarily) an Engineer Make: Career Decision Making among Undergraduate Engineering Majors." Journal of Engineering Education 98 (3): 227-34.

Lumsdaine, Monika, and Edward Lumsdaine. "Thinking preferences of engineering students: Implications for curriculum restructuring." Journal of Engineering Education 84, no. 2 (1995): 193-204.

Markus, Hazel, and Paula Nurius. 1986. "Possible Selves.” American Psychologist 41 (9): 954.

Marra, Rose M, Kelly A Rodgers, Demei Shen, and Barbara Bogue. 2009. "Women Engineering Students and Self-Efficacy: A Multi-Year, Multi-Institution Study of Women Engineering Student Self-Efficacy.” Journal of Engineering Education 98 (1): 27-38.

Marshall, Helen, Lynne McClymont, and Lucy Joyce. 2007. "Public Attitudes to and Perceptions of Engineering and Engineers 2007." Report, The Royal Academy of Engineering \& The Engineering and Technology Board, UK.

McGough, Catherine, Adam Kirn, and Lisa Benson. 2016. "Work in Progress:

Developing a Quantitative Instrument for Measuring Undergraduate Engineering Students' Future Time Perspectives.” In American Society for Engineering Education Annual Conference \& Exposition. New Orleans, LA.

Morelock, John R. "A systematic literature review of engineering identity: definitions, factors, and interventions affecting development, and means of 
measurement" European Journal of Engineering Education 42, no. 6 (2017): $1240-1262$.

Moses, Laurie, Cathy Hall, Karl Wuensch, Karen De Urquidi, Paul Kauffmann, William Swart, Steve Duncan, and Gene Dixon. "Are math readiness and personality predictive of first-year retention in engineering?" The Journal of Psychology, 145, no. 3 (2011): 229-245.

Nelson, Katherine G., Duane F. Shell, Jenefer Husman, Evan J. Fishman, and LeenKiat Soh. "Motivational and self- regulated learning profiles of students taking a foundational engineering course." Journal of Engineering Education 104, no. 1 (2015): 74-100.

Neumann, Ruth. 2001. “Disciplinary Differences and University Teaching.” Studies in Higher Education 26 (2): 135-46.

Noftle, Erik E, and Richard W Robins. "Personality predictors of academic outcomes: big five correlates of GPA and SAT scores." Journal of Personality and Social Psychology 93, no. 1 (2007): 116-130.

O'Connor, Melissa C, and Sampo V Paunonen. "Big Five personality predictors of postsecondary academic performance." Personality and Individual differences 43, no. 5 (2007): 971-990.

Ohland, Matthew W, Sheri D Sheppard, Gary Lichtenstein, Ozgur Eris, Debbie Chachra, and Richard A Layton. 2008. "Persistence, Engagement, and Migration in Engineering Programs." Journal of Engineering Education 97 (3): 259-78.

Osborne, George, and S Javid. 2015. "Fixing the Foundations: Creating a More Prosperous Nation" 10.

Oyserman, Daphna. 2004. "Self-Concept and Identity." In Perspectives on Social Psychology. Self and Social Identity, edited by M B Brewer and M Hewstone, 5-24. Blackwell Publishing.

Perez, Tony, Jennifer G Cromley, and Avi Kaplan. 2014. "The Role of Identity Development, Values, and Costs in College STEM Retention.” Journal of Educational Psychology 106 (1): 315.

Pierrakos, Olga, Thi Kay TK K Beam, Jamie Constantz, Aditya Johri, and Robin Anderson. 2009. "On the Development of a Professional Identity: Engineering Persisters vs Engineering Switchers." In American Society for Engineering 
Education Annual Conference \& Exposition, 1-6. FIE’09. Ieee.

https://doi.org/10.1109/FIE.2009.5350571.

Potvin, Geoff, and Zahra Hazari. "The development and measurement of identity across the physical sciences." In Proceedings of the Physics Education Research Conference (PERC), Portland, OR. 2013.

Prince, Michael. 2004. "Does Active Learning Work? A Review of the Research." Journal of Engineering Education 93 (3): 223-31. https://doi.org/10.1002/j.2168-9830.2004.tb00809.x.

R Core Team. 2018. "R: A Language and Environment for Statistical Computing." Vienna, Austria: R Foundation for Statistical Computing. http://www.rproject.org/.

Rachlin, Howard. 1995. "Self-Control: Beyond Commitment.” Behavioral and Brain Sciences 18 (1 1): 109-21.

Rayman, Paula, and Belle Brett. 1995. "Women Science Majors: What Makes a Difference in Persistence after Graduation?" The Journal of Higher Education 66 (4): $388-414$.

Raynor, Joel O. 1969. "Future Orientation and Motivation of Immediate Activity: An Elaboration of the Theory of Achievement Motivation." Psychological Review 76 (6): 606.

Renninger, K. Ann, Suzanne Hidi, Andreas Krapp, and Ann Renninger. The role of interest in learning and development. Psychology Press, 2014.

Rodríguez-Simmonds, Héctor E., Nelson S. Pearson, Jacqueline A. Rohde, Kyle P. Vealey, Adam Kirn, and Allison Godwin. 2017. "Forget Diversity, Our Project is Due." In American Society of Engineering Education Annual Conference \& Exposition. Columbus, OH. https://peer.asee.org/28378

Rohde, Jacqueline Ann, Lisa Benson, Geoff Potvin, Adam Kirn, and Allison Godwin. 2018. "You Either Have It or You Don't: First Year Engineering Students' Experiences of Belongingness.” In American Society of Engineering Education Annual Conference \& Exposition. Salt Lake City, UT. https://peer.asee.org/31320.

Royal Academy of Engineering. 2016. "The Diversity Programme 2011-2016." Report, The Royal Academy of Engineering. www.raeng.org.uk/diversityreport2016. 
Scheidt Matthew, Godwin Allison, Senkpeil Ryan R., Ge Julianna S., Chen John, Self Brian P., Widmann James M., and Edward J Berger. 2018. "Validity Evidence for the SUCCESS Survey: Measuring Non-Cognitive and Affective Traits of Engineering and Computing Students." In American Society for ENgineering Education Annual Conference \& Exposition, Salt Lake City, UT.

Scott, Norman A, and William E Sedlacek. 1975. "Personality Differentiation and Prediction of Persistence in Physical Science and Engineering." Journal of Vocational Behavior 6 (2): 205-16.

Seginer, Rachel. 2006. 'Parents' Educational Involvement: A Developmental Ecology Perspective." Parenting: Science and Practice 6 (1): 1-48.

Seymour, Elaine, and Nancy Hewitt. 1997. Talking about Leaving: Why

Undergraduates Leave the Sciences. Boulder, CO: Westview Press.

Shell, Duane F, and Jenefer Husman. 2001. "The Multivariate Dimensionality of

Personal Control and Future Time Perspective Beliefs in Achievement and SelfRegulation." Contemporary Educational Psychology 26 (4): 481-506.

Shell, Duane F., and Jenefer Husman. "Control, motivation, affect, and strategic selfregulation in the college classroom: A multidimensional phenomenon." Journal of Educational Psychology 100, no. 2 (2008): 443.

Sheu, Hung-Bin, and Jennifer J Bordon. 2017. "SCCT Research in the International Context: Empirical Evidence, Future Directions, and Practical Implications.” Journal of Career Assessment 25 (1): 58-74.

Singh, Romila, Nadya A Fouad, Mary E Fitzpatrick, Jane P Liu, Kevin J Cappaert, and Catia Figuereido. 2013. "Stemming the Tide: Predicting Women Engineers" Intentions to Leave." Journal of Vocational Behavior 83 (3): 281-94.

Smith, Gary, and Natasha Walsh. 2018. "Student Statistics." Student Registry and Services. University College London. http://www.ucl.ac.uk/srs/statistics.

Smith, Kathleen N, and Joy Gaston Gayles. 2017. “'Setting Up for the Next Big Thing”: Undergraduate Women Engineering Students' Postbaccalaureate Career Decisions.” Journal of College Student Development 58 (8): 1201-17.

Sola, Eric, Robert Hoekstra, Stephen Fiore, and Pamela McCauley. 2017. “An Investigation of the State of Creativity and Critical Thinking in Engineering Undergraduates." Creative Education 8 (9): 1495.

Sorensen, Eva. 2016. "Changing the World.” The Chemical Engineer, October. 
Szumilas, Magdalena. 2010. "Explaining Odds Ratios." Journal of the Canadian Academy of Child and Adolescent Psychiatry 19 (3): 227-29.

Teachman, Jay D., and Kathleen Paasch. 1998. "The Family and Educational Aspirations." Journal of Marriage and the Family, 704-14.

UK Space Agency. 2017. “2018 Will Be the Year of Engineering.” Gov.UK. 2017. https://www.gov.uk/government/news/2018-will-be-the-year-of-engineering.

Verdín, Dina, Allison Godwin, Adam Kirn, Lisa Benson, and Geoff Potvin. 2018. "Understanding How Engineering Identity and Belongingness Predict Grit for First-Generation College Students." In The Collaborative Network for Engineering and Computing Diversity Conference. Crystal City, VA.

_. "Engineering Women's Attitudes and Goals in Choosing Disciplines with Above and Below Average Female Representation." Social Sciences 7, no. 3 (2018): 1-25.

Vianello, Michelangelo, Egidio Robusto, and Pasquale Anselmi. "Implicit conscientiousness predicts academic performance." Personality and Individual Differences 48, no. 4 (2010): 452-457.

Wilson, Denise, Diane Jones, Fraser Bocell, Joy Crawford, Mee Joo Kim, Nanette Veilleux, Tamara Floyd-Smith, Rebecca Bates, and Melani Plett. 2015. "Belonging and Academic Engagement among Undergraduate STEM Students: A Multi-Institutional Study." Research in Higher Education 56 (7): 750-76. 